Correction

\title{
Correction: SNiPER: a novel hypermethylation biomarker panel for liquid biopsy based early breast cancer detection
}

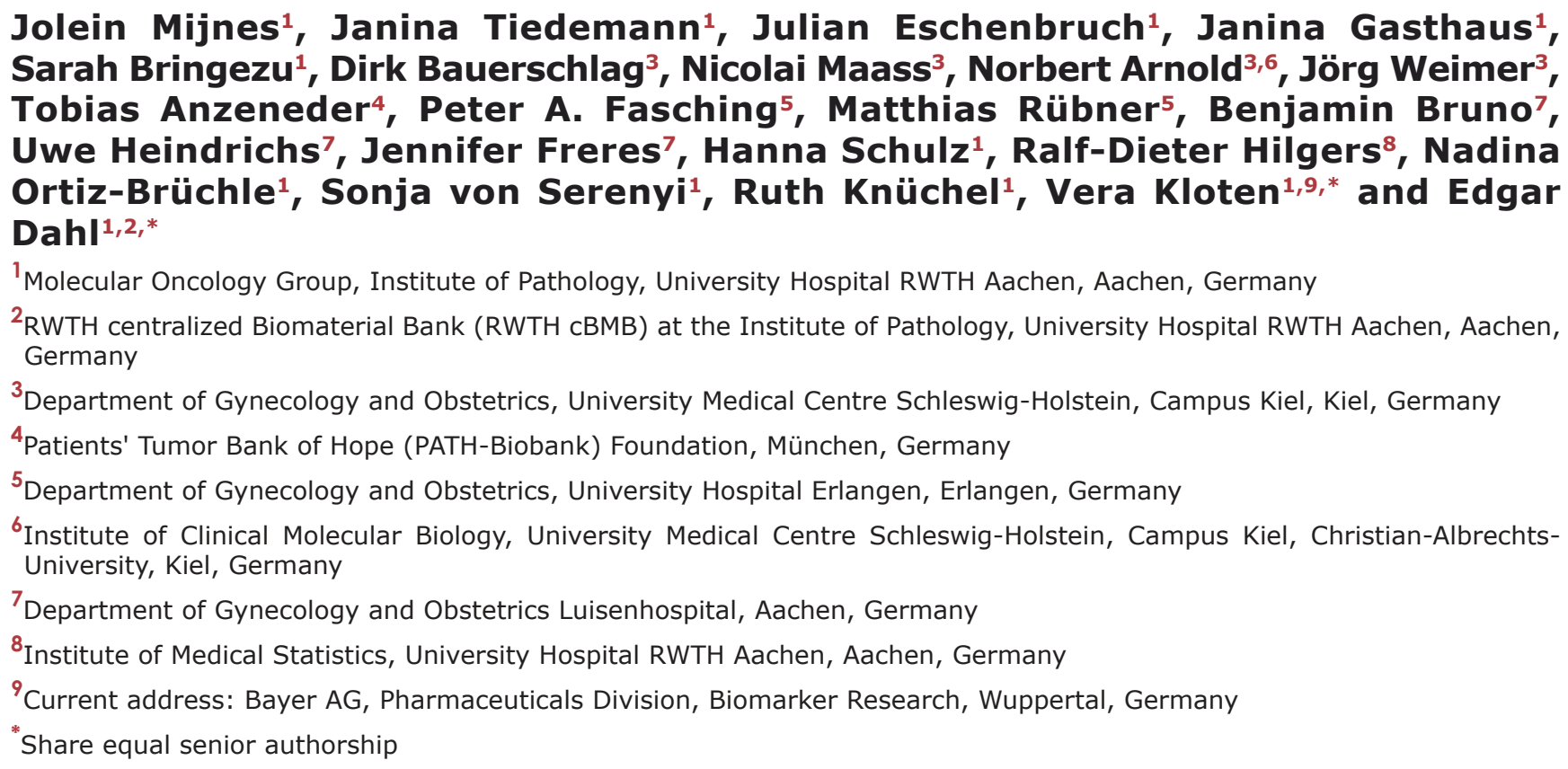

Jolein Mijnes ${ }^{1}$, Janina Tiedemann ${ }^{1}$, Julian Eschenbruch ${ }^{1}$, Janina Gasthaus ${ }^{1}$, Sarah Bringezu ${ }^{1}$, Dirk Bauerschlag ${ }^{3}$, Nicolai Maass ${ }^{3}$, Norbert Arnold ${ }^{3,6}$, Jörg Weimer ${ }^{3}$, Tobias Anzeneder ${ }^{4}$, Peter A. Fasching ${ }^{5}$, Matthias Rübner ${ }^{5}$, Benjamin Bruno ${ }^{7}$, Uwe Heindrichs ${ }^{7}$, Jennifer Freres ${ }^{7}$, Hanna Schulz ${ }^{1}$, Ralf-Dieter Hilgers ${ }^{8}$, Nadina Ortiz-Brüchle ${ }^{1}$, Sonja von Serenyi ${ }^{1}$, Ruth Knüchel ${ }^{1}$, Vera Kloten ${ }^{1,9, *}$ and Edgar Dahl ${ }^{1,2, *}$

${ }^{1}$ Molecular Oncology Group, Institute of Pathology, University Hospital RWTH Aachen, Aachen, Germany

${ }^{2}$ RWTH centralized Biomaterial Bank (RWTH CBMB) at the Institute of Pathology, University Hospital RWTH Aachen, Aachen, Germany

${ }^{3}$ Department of Gynecology and Obstetrics, University Medical Centre Schleswig-Holstein, Campus Kiel, Kiel, Germany

${ }^{4}$ Patients' Tumor Bank of Hope (PATH-Biobank) Foundation, München, Germany

${ }^{5}$ Department of Gynecology and Obstetrics, University Hospital Erlangen, Erlangen, Germany

${ }^{6}$ Institute of Clinical Molecular Biology, University Medical Centre Schleswig-Holstein, Campus Kiel, Christian-AlbrechtsUniversity, Kiel, Germany

7 Department of Gynecology and Obstetrics Luisenhospital, Aachen, Germany

${ }^{8}$ Institute of Medical Statistics, University Hospital RWTH Aachen, Aachen, Germany

${ }^{9}$ Current address: Bayer AG, Pharmaceuticals Division, Biomarker Research, Wuppertal, Germany

"Share equal senior authorship

Published: July 28, 2020

Copyright: Mijnes et al. This is an open-access article distributed under the terms of the Creative Commons Attribution License 3.0 (CC BY 3.0), which permits unrestricted use, distribution, and reproduction in any medium, provided the original author and source are credited.

TThis article has been corrected: The Grant section information has been updated with the following logos:

Original article: Oncotarget. 2019; 10:6494-6508. https://doi.org/10.18632/oncotarget.27303

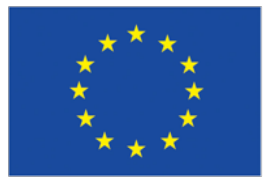

EUROPÄISCHE UNION Investition in unsere Zukunft

Europäischer Fonds

für regionale Entwicklung

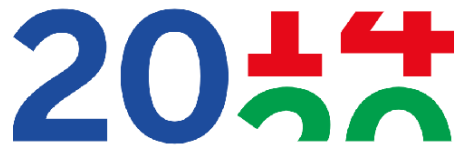

\section{EFRE.NRW}

Investitionen in Wachstum

und Beschäftigung

Ministerium für Wirtschaft, Innovation,

Digitalisierung und Energie des Landes Nordrhein-Westfalen

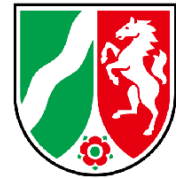

